Article

\title{
Impact of Nutritional Status on Gastroenteropancreatic Neuroendocrine Tumors (GEP-NET) Aggressiveness
}

\author{
Luigi Barrea ${ }^{1, t, * \mathbb{C}}$, Barbara Altieri ${ }^{1,2,+} \mathbb{C}$, Giovanna Muscogiuri ${ }^{1}$, Daniela Laudisio ${ }^{1}(\mathbb{D}$, \\ Giuseppe Annunziata ${ }^{3}{ }^{-1}$, Annamaria Colao ${ }^{1}$, Antongiulio Faggiano ${ }^{1}$ and Silvia Savastano ${ }^{1}$ (D) \\ 1 Dipartimento di Medicina Clinica e Chirurgia, Unit of Endocrinology, Federico II University Medical School \\ of Naples, Via Sergio Pansini, 5, 80131 Naples, Italy; altieri.barbara@gmail.com (B.A.); \\ giovanna.muscogiuri@gmail.com (G.M.); daniela.laudisio@libero.it (D.L.); colao@unina.it (A.C.); \\ afaggian@unina.it (A.F.); sisavast@unina.it (S.S.) \\ 2 Division of Endocrinology and Diabetes, Department of Internal Medicine I, University Hospital, \\ University of Wuerzburg, 97080 Wuerzburg, Germany \\ 3 Department of Pharmacy, University of Naples "Federico II", Italy; Via Domenico Montesano, 49, \\ 80131 Naples, Italy; giuseppe.annunziata@unina.it \\ * Correspondence: luigi.barrea@unina.it; Tel.: +39-081-746-3779 \\ $\dagger$ These authors contributed equally to this work.
}

Received: 29 October 2018; Accepted: 22 November 2018; Published: 1 December 2018

\begin{abstract}
Neuroendocrine tumors (NETs) are rare neoplasms mostly originating from the gastroenteropancreatic tract (GEP-NETs). Data regarding nutritional status in GEP-NET patients are limited. The aim of the study was to investigate the nutritional status and adherence to the Mediterranean Diet (MD) in GEP-NET patients and to correlate them with tumor aggressiveness. A cross-sectional case-control observational study was conducted enrolling 83 patients with well-differentiated G1/G2 GEP-NETs after resection, as well as 83 healthy subjects, age, sex and body mass index-matched. Nutritional status was assessed by evaluating with Bioelectrical Impedance analysis and its phase angle (PhA), adherence to the MD according to PREDIMED score, dietary assessment, anthropometric parameters, and clinico-pathological characteristics. GEP-NET patients consumed less frequently vegetables, fruits, wine, fish/seafood, nuts, and more frequently red/processed meats, butter, cream, margarine, and soda drinks than controls. Patients with more aggressive disease presented a lower adherence to MD according to PREDIMED categories in comparison to G1, localized and free/stable disease status. A smaller PhA value and a lower PREDIMED score were significantly correlated with G2 tumor, metastases, and progressive disease. To the best of our knowledge, this is the first study reporting an association between nutritional status and tumor aggressiveness in a selected group of GEP-NETs. Moreover, higher intakes of food of MD, may represent a potential tool for prevention of tumor aggressiveness. Thus, a skilled nutritionist should be an integral part of the multidisciplinary management of GEP-NET patients.
\end{abstract}

Keywords: gastroenteropancreatic neuroendocrine tumors; nutrition; tumor aggressiveness; Mediterranean diet; bioelectrical impedance analysis

\section{Introduction}

Neuroendocrine tumors (NETs) are rare neoplasms, with an estimated annual incidence of $\sim 6.9$ per 100,000 . More than $50 \%$ of these tumors originate from the digestive system and are referred to as gastroenteropancreatic NETs (GEP-NETs) [1]. The majority of GEP-NETs are diagnosed as incidental findings or due to clinical manifestation related to tumor mass (non-functioning NETs) [2]. In about 
$30 \%$ of cases, symptoms are related to hypersecretion of hormones and other biologically active molecules (functioning NETs) which can induce different metabolic and gastrointestinal impairments, such as hypoglycemia, hyperglycemia, peptic ulcers, diarrhea, steatorrhea, and altered gastrointestinal motility [3]. Thus, tumor hypersecretion as well as the surgical approach in altering the anatomy of the gastrointestinal tract, the somatostatin analogs treatment affecting the gut's secretion, motility and absorption, and systemic chemotherapy causing anorexia and weight loss, may all lead to an alteration of the nutritional status in patients affected by GEP-NET [4].

Despite the nutritional status being largely affected in GEP-NET patients, only few studies have investigated this topic. Recently, it was demonstrated that metabolic profile in patients with non-functioning GEP-NET was associated with higher ki67\% index and larger tumor size [5]. In contrast to this, a large analysis using the Nationwide Inpatient Sample showed that obesity could represent a protective factor against inpatient mortality in abdominal NET patients [6]. The same study also reported that malnutrition correlated with nearly 5-fold higher odds of inpatient mortality in this group of patients [6]. It has been suggested that a poor nutritional status may negatively impact the clinical outcome of patients with NET, extending the duration of hospitalization and reducing the overall-survival [7,8]. Moreover, malnourished NET patients showed a worse response to transcatheter arterial chemoembolization of liver metastases [9]. Maasberg et al. observed an association between nutritional status and body composition evaluated through Bioelectrical Impedance Analysis (BIA) and its derived parameter Phase Angle (PhA) in NET patients [8], as already reported in other cancer types $[10,11]$. Particularly, the authors reported that malnutrition significantly correlated with poorer BIA parameters and decreased PhA value [8]. No further details on nutritional status, dietary pattern, and body composition in GEP-NET patients have been reported.

Evidence suggests that nutritional factors, such as the scarce adherence to the Mediterranean diet (MD), could influence the aggressiveness of different tumor types, such as prostate, bladder, and breast cancer [12-14], in addition to representing a dietary pattern suitable in both prevention and mortality reduction of several cancer types [15]. Moreover, it has been reported that a low adherence to the MD correlated with an increased risk of metabolic syndrome [16], that, as above mentioned, was associated with larger and higher proliferative tumor in GEP-NET patients [5]. Recently, an association between PhA measurements and adherence to the MD independently from confounding factors, such as sex, age, and body weight in healthy subjects was observed [17]. Nowadays, nutritional guidelines in GEP-NET patients are still missing and there is no evidence regarding the association between the adherence to the MD and its potential association with tumor aggressiveness in patients with GEP-NET. Thus, the evaluation of PhA value and the adherence to the MD could be particularly useful to predict the nutritional status of GEP-NET patients.

The aim of this case-control, cross-sectional study was to investigate the nutritional status, including adherence to the MD and dietary pattern, in a selected group of GEP-NET patients and to evaluate the association of the nutritional status with different markers of tumor aggressiveness.

\section{Materials and Methods}

\subsection{Design and Setting}

This paper presnents a cross-sectional case-control observational study carried out at the European Neuroendocrine Tumor Society (ENETS) Center of Excellence Multidisciplinary Group for Neuroendocrine Tumors, Department of Clinical Medicine and Surgery, Unit of Endocrinology, University "Federico II" of Naples. Both patients and controls were enrolled from January 2017 to July 2018. The work was conducted in accordance with the Code of Ethics of the World Medical Association (Declaration of Helsinki) for experiments involving humans, and approved by the Ethical Committee of the University of Naples "Federico II" Medical School (n. 201/17). The protocol was explained to both patients and controls, and a written informed consent was obtained. This cross-sectional observational study was registered at clinicaltrials.gov with the number NCT03592940. 


\subsection{Population Study}

The study was conducted on 83 adult patients affected by GEP-NET out of 172 unselected Caucasian patients with a diagnosis of NET attending the ENETS Centers of Excellence Multidisciplinary Group for Neuroendocrine Tumors, University "Federico II", Naples. To improve the power of the study and the homogeneity of the investigated cohort, only patients with the following criteria were included:

- Histological diagnosis of well-differentiated, low grade (G)1 and G2 GEP-NET, including sporadic tumors or patients with multiple endocrine neoplasia type 1 (MEN1) syndrome, according to classification of by the World Health Organization (WHO) [18];

- Non-functioning GEP-NET patients that were treatment-naïve (evaluated at the moment of the diagnosis or before starting any medical treatment), or that discontinued Somatostatin Analogues (SSAs) for more than 6 months or after endoscopic surgery performed more than 6 months before the visit;

- Functioning GEP-NET patients who underwent endoscopic tumor resection and who were biochemically free of disease for more than 6 months and who had not resumed medical treatment; Patients with one or more of the following criteria were excluded from the study:

- Histological diagnosis of well-differentiated/high grade G3 GEP-NET or poorly-differentiated neuroendocrine carcinomas (NEC) according to WHO classification [18], since it has been shown that patients with G3 tumors were at risk of malnutrition [8];

- Diagnosis of bronchial or thymic NET, medullary thyroid cancer, Merkel cell carcinoma, pheochromocytoma/paraganglioma;

- Ongoing medical treatment, including SSAs or targeted therapy, at the moment of the visit, since they could affect the gastrointestinal secretory, motor, and absorptive functions or cause anorexia and liver toxicity [5];

- Patients who had undergone major surgery, since it could change the anatomy of the gastrointestinal tract;

- Patients with functioning GEP-NET that had been treated with curative surgery for less than 6 months before the visit;

- Patients with functioning GEP-NET that had not been treated at the moment of the visit, since the secretion of hormones, peptides and amines could cause malabsorption, diarrhea, steatorrhea and altered motility of the gastrointestinal tract [5];

- Patients on a hypocaloric diet in the last three months or specific nutritional regimens, including vegan or vegetarian diets and vitamin/mineral or antioxidant supplementation;

- Presence of clinical conditions that could influence fluid balance and metabolism, including diabetes mellitus, hypertension, liver or renal failure, acute or chronic inflammatory diseases, history of cancer, based on a complete medical examination and laboratory investigations;

- Current administration of medicaments that could influence the fluid balance, including non-steroidal anti-inflammatory drugs, hormone replacement therapy, diuretics or laxative;

- Abuse of alcohol defined by the Diagnostic and Statistical Manual of Mental Disorders (DSM)-V criteria [19];

Patients with pacemakers due to the potential interference with the device.

Eighty-three patients were enrolled together with healthy volunteers from the hospital and employees from the same geographical area. Controls were matched by age, sex, and Body Mass Index (BMI) and none had a history of cancer, diabetes mellitus, hypertension, liver or renal failure, inflammatory disease, alcohol abuse and none of them consumed medicaments. To avoid the overlapping enrollment, none of the controls contemporarily participated in other trials during the period of this study. All the measurements were performed between 8 and $12 \mathrm{AM}$. All subjects were measured after an overnight fast. The flow chart of the studied subjects is shown in Figure 1. 


\section{2 patients affected by NET}

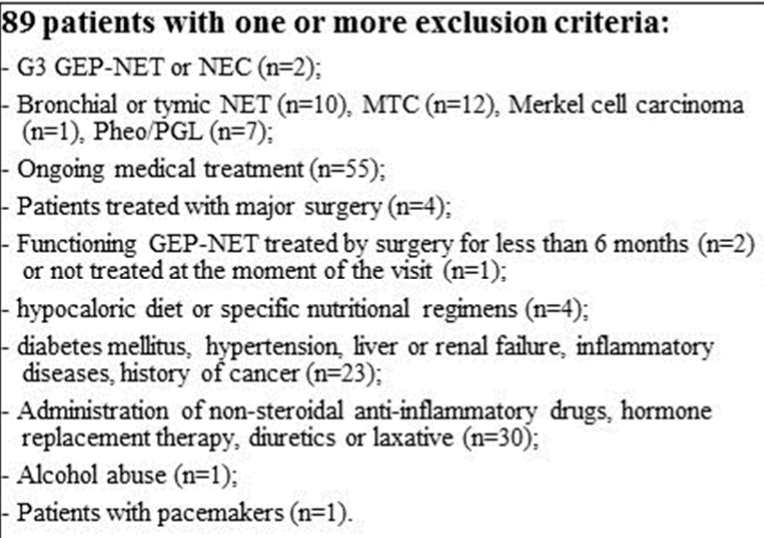

83 patients with GEP-NET G1/G2

Figure 1. Flow chart of the studied subjects. A total of 83 patients affected by well differentiated GEP-NET G1/G2 selected from 172 patients with NET attending the ENETS Centers of Excellence Multidisciplinary Group for Neuroendocrine Tumors, University "Federico II", Naples. Abbreviation: NET, Neuroendocrine Tumor; GEP-NET, Gastroenteropancreatic NET; MTC, medullary thyroid cancer; Pheo/PPG, Pheochromocytoma/paraganglioma; ENETS, European Neuroendocrine Tumor Society.

\subsection{Clinicopathological Characteristics of the Tumor}

Clinicopathological characteristics, such as primary tumor site and size, tumor stage, mitotic rate, ki67 index, metastases, familiar history of MEN1, hormonal secretion, comorbidity, treatment and follow-up, were collected for all patients.

Tumor size (mm) was defined as the maximum tumor diameter in the pathological specimen or in the last computed tomography (CT) scan/magnetic resonance imaging (MRI) when the patient had not undergone surgery or when the patient had multiple pancreatic nodules in case of MEN1. For these patients, the diameter of the biggest pancreatic lesion was considered for the tumor size. Only in a few cases $(n=3)$ was the tumor size not defined since the primary lesion had not been found. Tumor stage at diagnosis was classified according to the ENETS criteria [20]. According to this, patients were classified as those with localized disease (stage I-III) and patients with advanced disease (presence of metastases, stage IV).

For the diagnosis of NET, immunohistochemistry for chromogranin A, synaptophysin and ki67 were performed for all formalin-fixed paraffin-embedded tissue samples deriving from biopsy or surgery of the primary tumor and/or metastases [21]. Particularly, the evaluation of the mitotic rate and ki67\% index were performed as previously reported [22] according to ENETS criteria [20]. Additionally, according to WHO classification [18], all GEP-NETs were divided into well-differentiated or poorly differentiated malignant neoplasms named neuroendocrine carcinomas (NECs). In this study, only patients with well-differentiated/low grade GEP-NETs, graded as G1 (ki67\% $\leq 2 \%$ and mitoses $<2)$ or G2 (ki67\% 3-20\% and mitoses 2-20) were included [18]. 
At the time of the visit, disease status was defined as "disease free", when there was no biochemical and morphological evidence of the disease after tumor resection, "stable disease" or "progressive disease" according to RECIST 1.1 criteria [23].

\subsection{Lifestyle Habits}

Lifestyle habits, including physical activity level and smoking habits, were investigated by a standard questionnaire. Physical activity levels were expressed according to whether the participant habitually engaged at least $30 \mathrm{~min} /$ day of aerobic exercise (YES/NO). Subjects were considered as "current smokers" when they smoked at least one cigarette per day, "former smokers" when having stopped smoking at least one year before the interview, and "non-current smokers". Former and non-current smoker were considered as "no-smoker" for the analyses.

\subsection{Dietary Assessment}

As widely reported previously [24-27], data were obtained during a face-to-face interview between the patient and a qualified nutritionist. In detail, the dietary interview enabled the quantification of food and drinks by using a photographic food atlas $(\approx 1000$ photographs) of known portion sizes to ensure accurate completion of the records [28]. Dietary data, including beverage intakes and alcohol consumption, were collected by 7-day food records that were evaluated by a nutritionist. Data were stored and processed later, using a specific software (Terapia Alimentare Dietosystem ${ }^{\circledR}$ DS-Medica, (http://www.dsmedica.info) that calculate daily caloric intake and the quantities of macronutrients (animal and plant protein; total, complex and simple carbohydrates; total fat, saturated fatty acid (SFA), monounsaturated fatty acids (MUFA), polyunsaturated fatty acids (PUFA): n-6 PUFA, n-3 PUFA).

\subsection{Adherence to the Mediterranean Diet}

As previously reported [17,24-26,29-32], the adherence to the MD was evaluated using the 14-item questionnaire for the assessment of PREvención con DIeta MEDiterránea (PREDIMED) [33]. A qualified nutritionist administered the questionnaire during a face-to-face interview to all the enrolled subjects. Briefly, for each item scores 1 and 0 were assigned; the PREDIMED score was calculated as follows: $0-5$, lowest adherence; score 6-9, average adherence; score $\geq 10$, highest adherence [33].

\subsection{Anthropometric Measurements and Blood Pressure}

Anthropometric measurements were obtained with subjects wearing light clothes and without shoes. BMI was calculated by weight and height (weight $(\mathrm{kg})$ divided by height squared $\left(\mathrm{m}^{2}\right), \mathrm{kg} / \mathrm{m}^{2}$ ). Height was measured to the nearest $1 \mathrm{~cm}$ using a wall-mounted stadiometer (Seca 711; Seca, Hamburg, Germany). Body weight was derived to the nearest $50 \mathrm{~g}$ using a calibrated balance beam scale (Seca 711; Seca, Hamburg, Germany). Subjects were classified by BMI according to WHO's criteria as normal weight (BMI 18.5-24.9 $\mathrm{kg} / \mathrm{m}^{2}$ ), overweight (BMI $25.0-29.9 \mathrm{~kg} / \mathrm{m}^{2}$ ), grade I obesity (BMI $30.0-34.9 \mathrm{~kg} / \mathrm{m}^{2}$ ), grade II obesity (BMI $35.0-39.9 \mathrm{~kg} / \mathrm{m}^{2}$ ), grade III obesity (BMI $\geq 40.0 \mathrm{~kg} / \mathrm{m}^{2}$ ) [34]. Waist Circumference (WC) was measured to the closest $0.1 \mathrm{~cm}$ at the natural indentation or at a midway level between lower edge of the rib cage and iliac crest if no natural indentation was visible using a non-stretchable measuring tape, in line with the National Center for Health Statistics (NCHS) [35]. In all individuals systolic (SBP) and diastolic (DBP) blood pressure were measured three times, every two min after the subject had been sitting for at least $10 \mathrm{~min}$, with a random sphygmomanometer (Gelman Hawksley Ltd., Sussex, UK). The mean of the second and third reading was recorded.

\subsection{Assay Methods}

Samples were collected in the morning between 8 and 10 a.m., after an overnight fast of at least $8 \mathrm{~h}$ and stored at $-80^{\circ} \mathrm{C}$ until being processed. All biochemical analyses including fasting plasma glucose, 
total cholesterol, fasting plasma triglycerides were performed with a Roche Modular Analytics System in the Central Biochemistry Laboratory of our Institution. Low-density lipoprotein (LDL) cholesterol and high-density lipoprotein (HDL) cholesterol were determined by a direct method (homogeneous enzymatic assay for the direct quantitative determination of LDL and HDL cholesterol).

\subsection{Bioelectrical Impedance Analysis}

Bioelectrical impedance analysis was performed using a BIA phase-sensitive system by experienced observers (an 800- $\mu$ A current at a frequency single-frequency of $50 \mathrm{kHz}$ BIA 101 RJL, Akern Bioresearch, Florence-Italy) [36], as already amply reported in previous studies [17,29,37]. Based on the European Society of Parenteral and Enteral Nutrition (ESPEN) guidelines [38], all participants were supine with limbs slightly spread apart from the body, had refrained from eating, drinking, and exercising for six hours with no alcohol within $24 \mathrm{~h}$ before testing. Shoes and socks were removed and contact areas were scrubbed with alcohol immediately before electrode placement. Electrodes (BIATRODES Akern Srl; Florence-Italy) were placed on the dorsal surface of the right hand proximal to the phalangeal-metacarpal joint and on the superior surface of the right foot distal to the transverse arch. Sensor electrodes were placed on the right wrist at the midpoint between the distal prominence of the radius and ulna, and on the right ankle between the medial and lateral malleoli, as described by Kushner et al. [39]. All measurements were performed under strictly standardized conditions by the author, using the same device in order to avoid interobserver and interdevice variability. The instrument was routinely checked with resistors and capacitors of known values. Reliability for within-day and between-day measurements by the same observer were $<2.7 \%$ for resistance $(\mathrm{R}),<2.9 \%$ for reactance $\left(\mathrm{X}_{\mathrm{c}}\right)$, and $<3.1 \%$ for $\mathrm{R},<2.4 \%$ for $\mathrm{X}_{\mathrm{c}}$, respectively. The coefficient of variation $(\mathrm{CV})$ of repeated measurements of $\mathrm{R}$ and $\mathrm{X}_{\mathrm{c}}$ at $50 \mathrm{kHz}$ was assessed in 14 patients ( 7 males and 7 females) by the same observer: CVs were $1.9 \%$ for $\mathrm{R}$ and $1.8 \%$ for $\mathrm{X}_{\mathrm{c}}$. The PhA was derived from conditions under $50 \mathrm{kHz}$ according to the following formula: $\mathrm{PhA}\left({ }^{\circ}\right.$, degrees $)=\operatorname{arctangent} \mathrm{Xc}_{\mathrm{c}} / \mathrm{R}\left(\left(\mathrm{Xc}_{\mathrm{c}} / \mathrm{R}\right) \times(180 / \pi)\right)$.

\subsection{Statistical Analysis}

The data distribution was evaluated by the Kolmogorov-Smirnov test and the abnormal data were normalized by logarithm. All variables were logarithmically transformed and back-transformed for presentation in tables and figures. The chi-square $\left(\chi^{2}\right)$ test was used to determine the significance of differences in the frequency distribution. Differences between GEP-NETs patients and the control group were analyzed by Student's paired $t$-test, while the differences among the several parameters with the disease status were analyzed by Student's unpaired $t$-test, followed by Bonferroni post hoc analysis. $p$ values $<0.05$ were considered as statistically significant.

Proportional Odds Ratio (OR) models, $p$-value, 95\% Interval Confidence (IC), and $\mathrm{R}^{2}$, were performed to assess the association among quantitative variables (grading system and metastasis). Multinomial logistic regression, $\chi^{2}, p$-value, and Akaike Information Criterion (AIC), were performed to model the relationship between the several parameters with the three groups of disease status (disease free, stable disease, and progressive disease). The correlations between the different variables were performed using Pearson $r$ correlation coefficients. Receiver operator characteristic (ROC) curve analysis was performed to determine sensitivity and specificity, area under the curve (AUC), and IC, as well as cut-off values for PhA and PREDIMED score in detecting Sartorius HS score above the median values in the HS patients. Test AUC for ROC analysis was also performed. For $\alpha$ level the 0.05 type I error was selected and for $\beta$ level the 0.20 type II error was selected. In these last analyses, only variables with a $p$-value $<0.05$ in the univariate analysis (partial correlation) were entered. Variables with a variance inflation factor (VIF) $>10$ were excluded to avoid multicollinearity. Values $\leq 5 \%$ were considered statistically significant. Data were analyzed using the MedCalc ${ }^{\circledR}$ package (Version 12.3.0 1993-2012 MedCalc Software bvba-MedCalc Software, Mariakerke, Belgium) and SPSS Software (PASW Version 21.0, SPSS Inc., Chicago, IL, USA). 


\section{Results}

\subsection{Patient Population}

A total of 83 patients $(\mathrm{F}: \mathrm{M}=43: 40)$, mean age 56.66 (18-80) years, affected by GEP-NET were included in the study. Mean size of the tumor was $24.96 \pm 23.79 \mathrm{~mm}$. Primary NET were located in the pancreas $(n=47,56.6 \%)$, stomach $(n=12,14.5 \%)$, small intestine $(n=14,16.9 \%)$, appendix $(n=5,6 \%)$, colon $(n=2,2.4 \%)$ and in a few cases the primary site was unknown $(n=3,3.6 \%)$. The majority of patients had non-functioning GEP-NET $(n=75,90.4 \%)$. Among patients with pancreatic NET, 39 were non-functioning (83\%), 5 were insulinomas $(10.6 \%), 2$ were gastrinomas $(4.2 \%)$ and 1 was VIPoma $(2.2 \%)$. All patients with functioning pancreatic NET underwent endoscopic surgery of the lesion at least 6 months before the visit. Twenty two patients (26.5\%) had a MEN1 syndrome.

According to the pathological parameters, the mitotic rate and ki67\% index, all GEP-NET were classified as well-differentiated tumor G1 $(n=48,57.8 \%)$ or G2 ( $n=35,42.2 \%)$. At diagnosis, 22 patients $(26.5 \%)$ had metastases (stage IV), the majority of them in the liver. At the moment of the visit considered for the study, 34 patients (41\%) were disease free, 28 (33.7\%) had stable disease and 21 (25.3\%) had progressive disease according to the RECIST1.1 criteria.

\subsection{Nutritional Status in GEP-NET Patients and Control Group}

Clinical and anthropometric characteristics, lifestyle habits, blood pressure, metabolic profile, and bioelectrical parameters deriving from BIA of GEP-NET patients compared to controls are shown in Table 1. To note, GEP-NET patients smoked less $(p=0.005)$, presented higher blood pressure values and a worse metabolic profile $(p<0.001)$, and had smaller PhA according to gender $(p<0.001)$ in comparison to the control group (Table 1).

Table 1. Demographic, clinical, metabolic, and bioelectrical parameters of GEP-NET patients compared to controls.

\begin{tabular}{|c|c|c|c|}
\hline Parameters & $\begin{array}{c}\text { GEP-NET Patients } \\
n .83\end{array}$ & $\begin{array}{c}\text { Control Group } \\
n .83\end{array}$ & $p$-Value \\
\hline \multicolumn{4}{|l|}{ Clinical characteristics } \\
\hline Gender-male & $40(48.2 \%)$ & $40(48.2 \%)$ & $0.877\left(\chi^{2}=0.02\right)$ \\
\hline Age-mean (range) & $56(18-80)$ & $57(23-82)$ & 0.307 \\
\hline \multicolumn{4}{|l|}{ Lifestyle Habits } \\
\hline Smoking-yes & $32(38.6 \%)$ & $51(61.4 \%)$ & $0.005\left(\chi^{2}=7.81\right)$ \\
\hline Physical activity-yes & $41(49.4 \%)$ & $45(54.2 \%)$ & $0.986\left(\chi^{2}=0.00\right)$ \\
\hline \multicolumn{4}{|l|}{ Anthropometric measurement } \\
\hline $\operatorname{BMI}\left(\mathrm{kg} / \mathrm{m}^{2}\right)$ & $27.79 \pm 5.57$ & $27.54 \pm 2.84$ & 0.859 \\
\hline $\mathrm{WC}(\mathrm{cm})$ & $92.76 \pm 15.38$ & $87.92 \pm 10.66$ & 0.050 \\
\hline \multicolumn{4}{|l|}{ Blood pressure } \\
\hline SBP (mmHg) & $123.79 \pm 12.16$ & $118.49 \pm 11.93$ & 0.010 \\
\hline $\mathrm{DBP}(\mathrm{mmHg})$ & $76.99 \pm 7.99$ & $73.86 \pm 6.87$ & 0.007 \\
\hline \multicolumn{4}{|l|}{ Metabolic profile } \\
\hline Fasting Glucose (mg/dL) & $109.52 \pm 16.51$ & $89.29 \pm 11.72$ & $<0.001$ \\
\hline Total cholesterol (mg/dL) & $194.83 \pm 41.19$ & $149.08 \pm 22.41$ & $<0.001$ \\
\hline HDL cholesterol (mg/dL) & $44.43 \pm 14.35$ & $50.45 \pm 8.67$ & $<0.001$ \\
\hline LDL cholesterol (mg/dL) & $123.35 \pm 40.85$ & $77.20 \pm 25.00$ & $<0.001$ \\
\hline Triglycerides (mg/dL) & $135.23 \pm 47.81$ & $107.22 \pm 26.57$ & $<0.001$ \\
\hline \multicolumn{4}{|l|}{ Bioelectrical variables } \\
\hline $\mathrm{R}(\Omega)$ & $514.23 \pm 80.21$ & $523.54 \pm 59.99$ & 0.279 \\
\hline$X_{\mathrm{c}}(\Omega)$ & $42.31 \pm 9.50$ & $52.19 \pm 8.13$ & $<0.001$ \\
\hline $\operatorname{PhA}\left({ }^{\circ}\right)$ & $4.73 \pm 0.88$ & $5.70 \pm 0.55$ & $<0.001$ \\
\hline $\operatorname{PhA}\left({ }^{\circ}\right)$ males & $4.69 \pm 0.86$ & $5.76 \pm 0.60$ & $<0.001$ \\
\hline $\operatorname{PhA}\left({ }^{\circ}\right)$ females & $4.76 \pm 0.91$ & $5.65 \pm 0.52$ & $<0.001$ \\
\hline
\end{tabular}

A $p$ value in bold type denotes a significant difference $(p<0.05)$. Abbreviation: GEP-NET, Gastroenteropancreatic Neuroendocrine Tumor; BMI, Body Mass Index; WC, Waist Circumference; SBP, Systolic Blood Pressure; DBP, Diastolic Blood Pressure; HDL, High-Density Lipoprotein; LDL, Low-Density Lipoprotein; R, Resistance; Xc, Reactance; PhA, Phase angle. 
Data on Mediterranean food frequencies were analyzed by using the 7-day food records. Even though no differences in energy intake were observed between the two groups, GEP-NET patients consumed a lower quantity of plant protein $(p=0.003)$, complex carbohydrate $(p<0.001)$, MUFA $(p=0.009)$ and n-3 PUFA $(p<0.001)$, and higher quantity of simple carbohydrate $(p<0.001)$ and n-6 PUFA $(p<0.001)$ than control subjects (Table S1).

Analyzing in details the frequency of the assumed dietary components included in the PREDIMED questionnaire, GEP-NET patients consumed vegetables less frequently ( $p=0.005)$, fruits $(p=0.001)$, wine $(p=0.013)$, fish/seafood $(p=0.005)$, nuts $(p<0.001)$, and more frequently red/processed meats $(p=0.017)$, butter, cream, margarine $(p=0.001)$ and soda drinks $(p=0.003)$; Table 2 . Therefore, the PREDIMED score was significantly lower in GEP-NET patients compared to control group (6.18 \pm 2.25 vs. $7.39 \pm 2.54 ; p=0.001)$. The PREDIMED score was positively correlated with PhA both in males and in females, in both GEP-NET patients $(r=0.724, p<0.001$ and $r=0.682, p<0.001$; respectively) and control ( $\mathrm{r}=0.919, p<0.001$ and $\mathrm{r}=0.859, p<0.001$; respectively).

Regarding the adherence to the MD, only $4.8 \%$ of GEP-NET patients vs $26.5 \%$ of controls presented a high adherence to this dietary regimen $(p=0.001)$; Table 2.

Table 2. Response frequency of dietary components included in the PREDIMED questionnaire of the GEP-NET patients and control group.

\begin{tabular}{|c|c|c|c|c|c|c|}
\hline \multirow[t]{2}{*}{ Questions of PREDIMED Questionnaire } & \multicolumn{2}{|c|}{$\begin{array}{c}\text { GEP-NET } \\
\text { Patients } \\
n .83\end{array}$} & \multicolumn{2}{|c|}{$\begin{array}{c}\text { Control } \\
\text { Group } \\
n .83\end{array}$} & \multirow[b]{2}{*}{$x^{2}$} & \multirow[b]{2}{*}{$p$-Values } \\
\hline & $n$ & $\%$ & $n$ & $\%$ & & \\
\hline Use of extra virgin olive oil as main culinary lipid & 78 & 94.0 & 79 & 95.2 & 0.00 & 1.000 \\
\hline Extra virgin olive oil $>4$ tablespoons & 49 & 59.0 & 52 & 62.7 & 0.10 & 0.751 \\
\hline Vegetables $\geq 2$ servings/day & 30 & 36.1 & 49 & 59.0 & 7.83 & 0.005 \\
\hline Fruits $\geq 3$ servings/day & 27 & 32.5 & 50 & 60.2 & 11.72 & 0.001 \\
\hline Red/processed meats $<1 /$ day & 25 & 30.1 & 41 & 49.4 & 5.66 & 0.017 \\
\hline Butter, cream, margarine $<1 /$ day & 63 & 75.9 & 40 & 48.2 & 12.38 & 0.001 \\
\hline Soda drinks $<1 /$ day & 34 & 41.0 & 54 & 65.1 & 8.73 & 0.003 \\
\hline Wine glasses $\geq 7 /$ week & 14 & 16.9 & 29 & 34.9 & 6.15 & 0.013 \\
\hline Legumes $\geq \overline{3} /$ week & 38 & 45.8 & 37 & 44.6 & 0.00 & 1.000 \\
\hline Fish/seafood $\geq 3 /$ week & 18 & 21.7 & 36 & 43.4 & 7.93 & 0.005 \\
\hline Commercial sweets and confectionery $\leq 2 /$ week & 43 & 51.8 & 39 & 47.0 & 0.22 & 0.641 \\
\hline Tree nuts $\geq 3 /$ week & 20 & 24.1 & 33 & 39.8 & 21.14 & $<0.001$ \\
\hline Poultry more than red meats & 41 & 49.4 & 43 & 51.8 & 0.02 & 0.876 \\
\hline $\begin{array}{l}\text { Use of sofrito sauce } \geq 2 \text { / week } \\
\text { PREDIMED categories }\end{array}$ & 33 & 39.8 & 31 & 37.3 & 0.03 & 0.873 \\
\hline Low adherence to the MD & 30 & 36.1 & 28 & 33.7 & 0.03 & 0.870 \\
\hline Average adherence to the MD & 49 & 59.0 & 33 & 39.8 & 5.42 & 0.019 \\
\hline High adherence to the MD & 4 & 4.8 & 22 & 26.5 & 13.18 & 0.001 \\
\hline
\end{tabular}

A $p$ value in bold type denotes a significant difference $(p<0.05)$. Abbreviation: GEP-NET, Gastroenteropancreatic Neuroendocrine Tumor; PREDIMED, PREvención con DIeta MEDiterránea; MD, Mediterranean Diet.

\subsection{Nutritional Status in GEP-NET Patients According to Tumor Grading, Stage and Disease Status}

Differences in age, anthropometric measurement, blood pressure, metabolic profile, bioelectrical variables, and nutritional assessment in the GEP-NET patients grouped by grading G1/G2 and stage are summarized in Table 3. Interestingly, patients with GEP-NET G2 and stage IV had significantly higher levels of SBP, fasting glucose, total and LDL cholesterol, triglycerides, and lower levels of HDL cholesterol as well as a lower PREDIMED score and PhA in comparison to patients with localized GEP-NET G1 (Table 3). 
Table 3. Demographic, clinical, metabolic, and bioelectrical parameters in the GEP-NET patients according to tumor grading and stage.

\begin{tabular}{|c|c|c|c|c|c|c|}
\hline Parameters & $\begin{array}{c}\text { G1 } \\
n .48\end{array}$ & $\begin{array}{c}\mathrm{G} 2 \\
\text { n. } 35\end{array}$ & $p$-Value & $\begin{array}{c}\text { Stage I-III } \\
\text { (Localized } \\
\text { Disease) } \\
n .61\end{array}$ & $\begin{array}{c}\text { Stage IV } \\
\text { (Metastases) } \\
n .22\end{array}$ & $p$-Value \\
\hline BMI $\left(\mathrm{kg} / \mathrm{m}^{2}\right)$ & $27.09 \pm 5.89$ & $28.74 \pm 5.01$ & 0.141 & $27.23 \pm 5.77$ & $29.31 \pm 4.75$ & 0.081 \\
\hline $\mathrm{WC}(\mathrm{cm})$ & $90.29 \pm 14.99$ & $96.15 \pm 15.46$ & 0.092 & $90.72 \pm 15.42$ & $98.41 \pm 14.05$ & 0.032 \\
\hline $\mathrm{DBP}(\mathrm{mmHg})$ & $75.83 \pm 7.88$ & $78.57 \pm 8.00$ & 0.130 & $76.15 \pm 7.27$ & $79.32 \pm 9.54$ & 0.213 \\
\hline \multicolumn{7}{|l|}{ Metabolic profile } \\
\hline Fasting Glucose (mg/dL) & $104.38 \pm 15.61$ & $116.57 \pm 15.23$ & 0.001 & $106.26 \pm 16.32$ & $118.54 \pm 13.64$ & 0.001 \\
\hline Total cholesterol (mg/dL) & $177.54 \pm 28.14$ & $218.54 \pm 44.67$ & $<0.001$ & $186.74 \pm 37.16$ & $217.27 \pm 44.26$ & 0.009 \\
\hline HDL cholesterol (mg/dL) & $46.97 \pm 11.77$ & $40.94 \pm 16.83$ & 0.007 & $47.00 \pm 13.94$ & $37.31 \pm 13.27$ & 0.002 \\
\hline LDL cholesterol (mg/dL) & $106.02 \pm 27.74$ & $147.13 \pm 44.21$ & $<0.001$ & $114.99 \pm 35.51$ & $146.55 \pm 46.31$ & 0.013 \\
\hline $\operatorname{PhA}\left({ }^{\circ}\right)$ & $5.26 \pm 0.62$ & $4.00 \pm 0.65$ & $<0.001$ & $4.93 \pm 0.80$ & $4.16 \pm 0.86$ & $<0.001$ \\
\hline \multicolumn{7}{|l|}{ Nutritional assessment } \\
\hline PREDIMED score & $7.56 \pm 1.28$ & $4.29 \pm 1.87$ & $<0.001$ & $6.69 \pm 2.05$ & $4.77 \pm 2.22$ & $<0.001$ \\
\hline Total energy (kcal) & $2223.29 \pm 235.67$ & $2307.88 \pm 235.47$ & 0.107 & $2256.96 \pm 231.39$ & $2264.49 \pm 260.66$ & 0.943 \\
\hline Protein (g of total kcal) & $94.59 \pm 12.21$ & $101.77 \pm 16.08$ & 0.026 & $96.21 \pm 12.29$ & $101.55 \pm 18.66$ & 0.191 \\
\hline Animal (g of total kcal) & $70.31 \pm 11.54$ & $73.77 \pm 10.25$ & 0.129 & $71.68 \pm 11.11$ & $71.99 \pm 11.26$ & 0.903 \\
\hline Plant (g of total kcal) & $24.29 \pm 10.01$ & $28.01 \pm 14.32$ & 0.236 & $24.52 \pm 10.42$ & $29.54 \pm 15.51$ & 0.178 \\
\hline Carbohydrate (g of total kcal) & $300.19 \pm 36.57$ & $308.89 \pm 34.06$ & 0.246 & $304.80 \pm 36.50$ & $301.25 \pm 33.58$ & 0.706 \\
\hline Complex (g of total kcal) & $188.41 \pm 23.05$ & $190.63 \pm 22.83$ & 0.633 & $190.53 \pm 23.27$ & $186.06 \pm 21.80$ & 0.431 \\
\hline Simple (g of total kcal) & $111.78 \pm 15.77$ & $118.27 \pm 14.01$ & 0.040 & $114.27 \pm 15.53$ & $115.19 \pm 15.02$ & 0.785 \\
\hline Fat (gr of total kcal) & $71.57 \pm 7.60$ & $73.91 \pm 9.57$ & 0.275 & $72.55 \pm 7.66$ & $72.59 \pm 10.73$ & 0.879 \\
\hline SFA (g of total kcal) & $25.79 \pm 5.16$ & $26.80 \pm 10.30$ & 0.664 & $26.03 \pm 6.55$ & $26.72 \pm 10.46$ & 0.829 \\
\hline
\end{tabular}

A $p$ value in bold type denotes a significant difference $(p<0.05)$. Abbreviation: GEP-NET, Gastroenteropancreatic Neuroendocrine Tumor; G, grading; BMI, Body Mass Index; WC, Waist Circumference; SBP, Systolic Blood Pressure; DBP, Diastolic Blood Pressure; HDL, High-Density Lipoprotein; LDL, Low-Density Lipoprotein; R, Resistance; Xc, Reactance; PhA, Phase angle; PREDIMED, PREvención con DIeta MEDiterránea; SFA, Saturated Fatty Acids; MUFA, MonoUnsaturated Fatty Acids; PUFA, PolyUnsaturated Fatty Acids.

Similar results were observed also when these parameters were correlated with disease status. GEP-NET patients with progressive disease showed a significantly worse metabolic profile, a smaller $\mathrm{PhA}(p<0.001)$, and a significantly lower PREDIMED score $(p<0.001)$ in comparison to patients who were free of the disease or with stable disease (Table 4).

When classified GEP-NET patients based on tumor grade G1/G2, stage and disease status, the majority of patients with aggressive disease (GEP-NET G2, stage IV and progressive disease) presented a low adherence to the MD according to PREDIMED categories (Figure 2 and Table S2).

In details, 28 out $35(80 \%)$ patients with G2 GEP-NET, 13 out $22(59 \%)$ patients with metastases and 15 out $21(71.4 \%)$ patients with progressive disease had significantly lower adherence to the MD (Figure 2). On the contrary, $87.5 \%, 65.5 \%$, and $67.7 \%$ of patients with GEP-NET G1, localized disease and free of disease, respectively, had an average adherence to the MD. Not one of the patients with aggressive tumor had a high adherence to the MD according to PREDIMED categories (Figure 2). No significant differences were observed when these patients were classified for gender, smoking and physical activity (Table S2). 
Table 4. Demographic, clinical, metabolic and bioelectrical parameters in the GEP-NET patients according to disease status.

\begin{tabular}{|c|c|c|c|c|}
\hline \multirow[b]{2}{*}{ Parameters } & \multicolumn{4}{|c|}{ Disease Status } \\
\hline & $\begin{array}{c}\text { Free of the Disease } \\
n .34\end{array}$ & $\begin{array}{c}\text { Stable Disease } \\
\text { n. } 28\end{array}$ & $\begin{array}{c}\text { Progressive Disease } \\
n .21\end{array}$ & $p$-Value \\
\hline Age (years) & $55.61 \pm 17.33$ & $57.71 \pm 15.23$ & $56.95 \pm 13.51$ & 0.720 \\
\hline \multicolumn{5}{|l|}{ Anthropometric measurement } \\
\hline BMI $\left(\mathrm{kg} / \mathrm{m}^{2}\right)$ & $27.21 \pm 4.94$ & $27.54 \pm 6.72$ & $29.06 \pm 4.83$ & 0.411 \\
\hline WC $(\mathrm{cm})$ & $90.93 \pm 16.20$ & $92.36 \pm 14.44$ & $96.26 \pm 15.36$ & 0.458 \\
\hline \multicolumn{5}{|l|}{ Blood pressure } \\
\hline $\mathrm{SBP}(\mathrm{mmHg})$ & $123.08 \pm 12.55$ & $121.79 \pm 11.07$ & $127.62 \pm 12.16$ & 0.256 \\
\hline $\mathrm{DBP}(\mathrm{mmHg})$ & $76.02 \pm 7.66$ & $77.14 \pm 7.75$ & $78.33 \pm 8.99$ & 0.631 \\
\hline \multicolumn{5}{|l|}{ Metabolic profile } \\
\hline Fasting Glucose (mg/dL) & $105.38 \pm 12.99$ & $106.82 \pm 16.87$ & $119.81 \pm 17.42$ & 0.005 \\
\hline Total cholesterol (mg/dL) & $195.67 \pm 41.66$ & $178.64 \pm 32.72$ & $215.05 \pm 42.99$ & 0.017 \\
\hline HDL cholesterol (mg/dL) & $42.15 \pm 13.94$ & $49.18 \pm 12.43$ & $41.81 \pm 14.35$ & 0.035 \\
\hline LDL cholesterol (mg/dL) & $126.23 \pm 38.67$ & $105.35 \pm 33.54$ & $142.70 \pm 44.65$ & 0.012 \\
\hline Triglycerides (mg/dL) & $136.50 \pm 41.33$ & $120.57 \pm 38.41$ & $152.71 \pm 62.74$ & 0.327 \\
\hline \multicolumn{5}{|l|}{ Bioelectrical variables } \\
\hline $\mathrm{R}(\Omega)$ & $512.71 \pm 83.84$ & $507.61 \pm 73.76$ & $525.52 \pm 85.06$ & 0.767 \\
\hline $\operatorname{Xc}(\Omega)$ & $41.65 \pm 9.88$ & $45.79 \pm 7.76$ & $38.76 \pm 9.84$ & 0.025 \\
\hline $\operatorname{PhA}\left({ }^{\circ}\right)$ & $4.66 \pm 0.82$ & $5.19 \pm 0.71$ & $4.22 \pm 0.91$ & $<0.001$ \\
\hline \multicolumn{5}{|l|}{ Nutritional assessment } \\
\hline PREDIMED score & $6.91 \pm 2.25$ & $6.54 \pm 1.79$ & $4.52 \pm 2.02$ & $<0.001$ \\
\hline Total energy (kcal) & $2256.94 \pm 257.14$ & $2254.24 \pm 204.66$ & $2268.51 \pm 257.36$ & 0.983 \\
\hline Protein (g of total kcal) & $96.82 \pm 13.50$ & $97.39 \pm 14.13$ & $99.22 \pm 16.36$ & 0.855 \\
\hline Animal (g of total kcal) & $71.87 \pm 10.06$ & $71.94 \pm 10.98$ & $71.37 \pm 13.18$ & 0.948 \\
\hline Plant (g of total kcal) & $24.96 \pm 10.62$ & $25.44 \pm 10.98$ & $27.85 \pm 15.63$ & 0.752 \\
\hline Carbohydrate (g of total kcal) & $302.62 \pm 37.01$ & $303.83 \pm 30.79$ & $305.91 \pm 40.54$ & 0.954 \\
\hline Complex (g of total kcal) & $188.00 \pm 23.11$ & $189.85 \pm 19.44$ & $190.84 \pm 27.26$ & 0.902 \\
\hline Simple (g of total kcal) & $114.61 \pm 15.60$ & $113.98 \pm 14.46$ & $115.07 \pm 16.62$ & 0.979 \\
\hline Fat (g of total kcal) & $73.24 \pm 9.49$ & $72.15 \pm 6.69$ & $72.00 \pm 9.31$ & 0.868 \\
\hline SFA (g of total kcal) & $27.26 \pm 7.87$ & $25.67 \pm 5.12$ & $25.24 \pm 10.17$ & 0.380 \\
\hline MUFA (g of total kcal) & $30.88 \pm 3.76$ & $31.40 \pm 3.22$ & $31.10 \pm 3.86$ & 0.824 \\
\hline PUFA (g of total kcal) & $15.10 \pm 6.12$ & $15.08 \pm 2.96$ & $15.65 \pm 4.53$ & 0.653 \\
\hline n-6 PUFA (gr/day) & $7.99 \pm 5.08$ & $7.71 \pm 2.77$ & $8.97 \pm 4.21$ & 0.385 \\
\hline n-3 PUFA (gr/day) & $7.11 \pm 1.99$ & $7.38 \pm 1.03$ & $6.68 \pm 2.10$ & 0.280 \\
\hline
\end{tabular}

A $p$ value in bold type denotes a significant difference $(p<0.05)$. Abbreviation: GEP-NET, Gastroenteropancreatic Neuroendocrine Tumor; BMI, Body Mass Index; WC, Waist Circumference; SBP, Systolic Blood Pressure; DBP, Diastolic Blood Pressure; HDL, High-Density Lipoprotein; LDL, Low-Density Lipoprotein; R, Resistance; Xc, Reactance; PhA, Phase angle; PREDIMED, PREvención con Dleta MEDiterránea; SFA, Saturated Fatty Acids; MUFA, MonoUnsaturated Fatty Acids; PUFA, PolyUnsaturated Fatty Acids.

A)

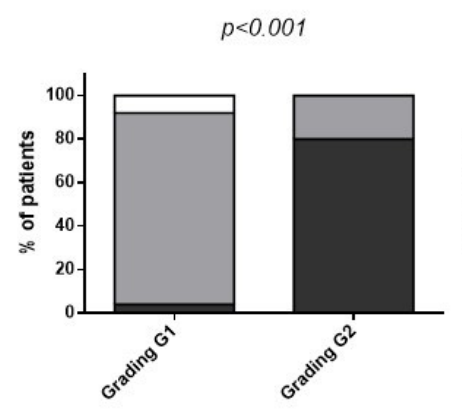

B)

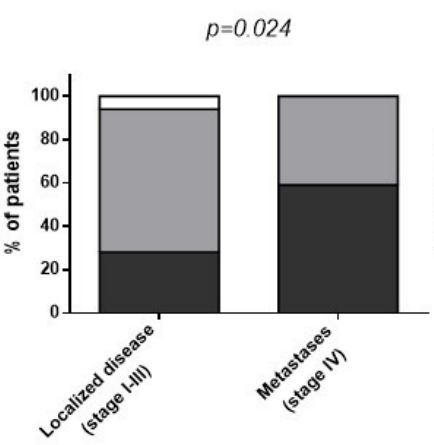

C)

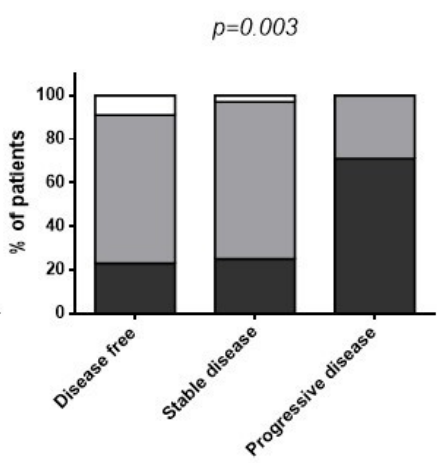

Figure 2. Adherence to the Mediterranean Diet according to PREDIMED categories in GEP-NET patients classified by tumor grade G1/G2 (A), stage (B), and disease status (C). Abbreviation: GEP-NET, Gastroenteropancreatic Neuroendocrine Tumor; PREDIMED, PREvención con DIeta MEDiterránea; MD, Mediterranean Diet.

\subsection{Correlation between Tumor Aggressiveness and Nutritional Status in GEP-NET Patients}

Different markers, such as grading, stage, progressive disease, ki67\% index, and tumor size, were evaluated to investigate tumor aggressiveness. 
To assess the association of grading and stage, a bivariate proportional OR model with age, anthropometric measurement, blood pressure, metabolic profile, bioelectrical variables, and nutritional assessment was performed (Table 5).

Table 5. Bivariate proportional odds ratio model performed to assess the association of tumor aggressiveness with demographic, clinical, metabolic, and bioelectrical parameters.

\begin{tabular}{|c|c|c|c|c|c|c|c|c|}
\hline \multirow{2}{*}{ Parameters } & \multicolumn{4}{|c|}{ Grading G2 } & \multicolumn{4}{|c|}{ Stage IV (Metastases) } \\
\hline & OR & $p$-Value & $95 \% \mathrm{CI}$ & $\mathbf{R}^{2}$ & OR & $p$-Value & $95 \% \mathrm{CI}$ & $\mathbf{R}^{2}$ \\
\hline Age (years) & 1.02 & 0.217 & $0.99-1.05$ & 0.019 & 1.02 & 0.359 & $0.98-1.05$ & 0.010 \\
\hline \multicolumn{9}{|l|}{ Anthropometric measurement } \\
\hline $\mathrm{BMI}\left(\mathrm{kg} / \mathrm{m}^{2}\right)$ & 1.06 & 0.191 & $0.97-1.15$ & 0.021 & 1.07 & 0.145 & $0.98-1.17$ & 0.026 \\
\hline $\mathrm{WC}(\mathrm{cm})$ & 0.07 & 0.049 & $0.99-1.06$ & 0.036 & 1.03 & 0.049 & $1.00-1.07$ & 0.048 \\
\hline \multicolumn{9}{|l|}{ Blood pressure } \\
\hline $\mathrm{SBP}(\mathrm{mmHg})$ & 1.05 & 0.018 & $1.01-1.09$ & 0.071 & 1.05 & 0.020 & $1.00-1.10$ & 0.069 \\
\hline $\mathrm{DBP}(\mathrm{mmHg})$ & 1.04 & 0.125 & $0.99-1.11$ & 0.029 & 1.05 & 0.114 & $0.99-1.12$ & 0.031 \\
\hline \multicolumn{9}{|l|}{ Metabolic profile } \\
\hline Fasting Glucose (mg/dL) & 1.06 & 0.002 & $1.02-1.09$ & 0.136 & 1.05 & 0.005 & $1.01-1.09$ & 0.108 \\
\hline Total cholesterol (mg/dL) & 1.03 & $<0.001$ & $1.02-1.05$ & 0.241 & 1.02 & 0.004 & $1.00-1.04$ & 0.108 \\
\hline HDL cholesterol (mg/dL) & 0.97 & 0.044 & $0.94-1.00$ & 0.045 & 0.93 & 0.011 & $0.88-0.98$ & 0.105 \\
\hline LDL cholesterol (mg/dL) & 1.03 & $<0.001$ & $1.02-1.05$ & 0.242 & 1.02 & 0.003 & $1.00-1.04$ & 0.114 \\
\hline Triglycerides $(\mathrm{mg} / \mathrm{dL})$ & 1.01 & 0.007 & $1.00-1.03$ & 0.094 & 1.02 & 0.001 & $1.00-1.04$ & 0.157 \\
\hline \multicolumn{9}{|l|}{ Bioelectical variables } \\
\hline $\mathrm{R}(\Omega)$ & 1.00 & 0.109 & $0.99-1.01$ & 0.032 & 1.00 & 0.667 & $0.99-1.00$ & 0.002 \\
\hline $\operatorname{Xc}(\Omega)$ & 0.88 & $<0.001$ & $0.83-0.95$ & 0.200 & 0.94 & 0.031 & $0.89-0.99$ & 0.060 \\
\hline $\operatorname{PhA}\left(^{\circ}\right)$ & 0.01 & $<0.001$ & $0.01-0.08$ & 0.529 & 0.31 & 0.001 & $0.15-0.64$ & 0.149 \\
\hline \multicolumn{9}{|l|}{ Nutritional assessment } \\
\hline PREDIMED score & 0.31 & $<0.001$ & $0.19-0.50$ & 0.486 & 0.66 & 0.001 & $0.51-0.85$ & 0.137 \\
\hline Total energy (kcal) & 1.00 & 0.113 & $1.00-1.01$ & 0.031 & 1.00 & 0.898 & $0.99-1.00$ & 0.000 \\
\hline Protein (g of total kcal) & 1.01 & 0.029 & $1.00-1.07$ & 0.061 & 1.02 & 0.042 & $0.99-1.06$ & 0.026 \\
\hline Animal (g of total kcal) & 1.03 & 0.164 & $0.98-1.07$ & 0.024 & 1.00 & 0.909 & $0.96-1.05$ & 0.000 \\
\hline Plant (g of total kcal) & 1.03 & 0.171 & $0.99-1.07$ & 0.023 & 1.03 & 0.002 & $0.99-1.08$ & 0.033 \\
\hline Carbohydrate (g of total kcal) & 1.00 & 0.272 & $0.99-1.02$ & 0.015 & 0.99 & 0.686 & $0.98-1.01$ & 0.002 \\
\hline Complex (g of total kcal) & 1.00 & 0.661 & $0.98-1.02$ & 0.002 & 0.99 & 0.430 & $0.97-1.01$ & 0.008 \\
\hline Simple (g of total kcal) & 1.03 & 0.042 & 0.99-1.06 & 0.044 & 1.00 & 0.808 & $0.97-1.04$ & 0.001 \\
\hline Fat (gr of total kcal) & 1.03 & 0.218 & $0.98-1.09$ & 0.019 & 1.00 & 0.983 & $0.95-1.06$ & 0.000 \\
\hline SFA ( $\mathrm{g}$ of total kcal) & 1.02 & 0.555 & $0.96-1.08$ & 0.004 & 1.01 & 0.136 & $0.95-1.08$ & 0.002 \\
\hline MUFA (g of total kcal) & 1.03 & 0.610 & $0.91-1.17$ & 0.003 & 0.99 & 0.954 & $0.87-1.14$ & 0.000 \\
\hline PUFA (g of total kcal) & 1.04 & 0.391 & $0.95-1.14$ & 0.009 & 0.97 & 0.614 & $0.87-1.09$ & 0.003 \\
\hline n-6 PUFA (g/day) & 1.07 & 0.081 & $0.96-1.20$ & 0.020 & 0.99 & 0.807 & $0.87-1.11$ & 0.001 \\
\hline n-3 PUFA (g/day) & 0.92 & 0.502 & $0.71-1.18$ & 0.005 & 0.89 & 0.428 & $0.68-1.18$ & 0.008 \\
\hline
\end{tabular}

A $p$ value in bold type denotes a significant difference $(p<0.05)$. Abbreviation: BMI, Body Mass Index; WC, Waist Circumference; SBP, Systolic Blood Pressure; DBP, Diastolic Blood Pressure; HDL, High-Density Lipoprotein; LDL, Low-Density Lipoprotein; R, Resistance; Xc, Reactance; PhA, Phase angle; PREDIMED, PREvención con DIeta MEDiterránea; SFA, Saturated Fatty Acids; MUFA, MonoUnsaturated Fatty Acids; PUFA, PolyUnsaturated Fatty Acids; OR, Odds Ratio; IC, Interval Confidence.

Metastatic G2 tumor were significantly associated with higher values of WC ( $p=0.049$ for both), SBP ( $p=0.018$ and $p=0.020$ for G2 and stage IV, respectively), metabolic profile $(p<0.001$ for total and LDL cholesterol, $p=0.002$ and $p=0.007$ for fasting glucose and triglycerides, respectively, and G2; $p=0.004, p=0.003, p=0.005$ and $p=0.001$ for total cholesterol, LDL cholesterol, fasting glucose and triglycerides, respectively, and stage IV), protein consumption ( $p=0.029$ and $p=0.042$ for G2 and stage IV, respectively), and with lower levels of HDL cholesterol ( $p=0.044$ and $p=0.011$ for G2 and stage IV, respectively), lower PhA ( $p<0.001$ and $p=0.001$ for G2 and stage IV, respectively) and PREDIMED score $(p<0.001$ and $p=0.001$ for G2 and stage IV, respectively; Table 5). In addition, GEP-NETs G2 were associated with higher consumption of simple carbohydrate $(p=0.042)$ and metastasized disease with lower consumption of plant protein $(p=0.002)$.

A multinomial logistic regression model to assess the association between patients with progressive disease and age, anthropometric measurement, blood pressure, metabolic profile, bioelectrical variables, and nutritional assessment was performed (Table 6). Progressive disease was associated with higher value of WC $(p=0.033)$, blood pressure $(p=0.05$ and $p=0.027$ for SBP and DBP, respectively), fasting glucose $(p=0.043)$, triglycerides $(p=0.030)$, and lower HDL cholesterol $(p=0.011)$, PhA $(p=0.010)$, and PREDIMED score $(p=0.005)$. 
Table 6. Multinomial logistic regression model to assess the association between disease status with age, anthropometric measurement, blood pressure, metabolic profile, bioelectrical variables and nutritional assessment.

\begin{tabular}{|c|c|c|c|}
\hline Parameters & $x^{2}$ & $\begin{array}{c}p \text { Value } \\
p \text { Vive Di }\end{array}$ & AIC \\
\hline Age (years) & 107.35 & 0.054 & 201.30 \\
\hline \multicolumn{4}{|l|}{ Anthropometric measurement } \\
\hline $\operatorname{BMI}\left(\mathrm{kg} / \mathrm{m}^{2}\right)$ & 176.49 & 0.125 & 317.39 \\
\hline $\mathrm{WC}(\mathrm{cm})$ & 156.71 & 0.033 & 266.41 \\
\hline \multicolumn{4}{|l|}{ Blood pressure } \\
\hline $\mathrm{SBD}(\mathrm{mmHg})$ & 28.64 & 0.050 & 75.82 \\
\hline $\mathrm{DBD}(\mathrm{mmHg})$ & 23.06 & 0.027 & 56.61 \\
\hline \multicolumn{4}{|l|}{ Metabolic profile } \\
\hline Fasting Glucose (mg/dL) & 116.57 & 0.043 & 215.48 \\
\hline Total cholesterol (mg/dL) & 140.08 & 0.220 & 277.92 \\
\hline HDL cholesterol (mg/dL) & 109.25 & 0.011 & 187.09 \\
\hline LDL cholesterol (mg/dL) & 168.17 & 0.147 & 309.55 \\
\hline Triglycerides (mg/dL) & 159.85 & 0.030 & 269.70 \\
\hline \multicolumn{4}{|l|}{ Bioelectical variables } \\
\hline $\mathrm{R}(\Omega)$ & 156.03 & 0.233 & 303.33 \\
\hline $\mathrm{X}_{\mathrm{c}}(\Omega)$ & 82.00 & 0.088 & 173.49 \\
\hline $\operatorname{PhA}\left({ }^{\circ}\right)$ & 85.71 & 0.010 & 154.83 \\
\hline \multicolumn{4}{|l|}{ Nutritional assessment } \\
\hline PREDIMED score & 32.24 & 0.005 & 70.80 \\
\hline Total energy (kcal) & 173.72 & 0.217 & 326.77 \\
\hline Protein (g of total kcal) & 179.26 & 0.196 & 332.00 \\
\hline Animal (g of total kcal) & 179.23 & 0.195 & 332.01 \\
\hline Plant (g of total kcal) & 179.25 & 0.197 & 331.09 \\
\hline Carbohydrate (g of total kcal) & 178.25 & 0.196 & 332.08 \\
\hline Complex (g of total kcal) & 179.26 & 0.199 & 332.00 \\
\hline Simple (g of total kcal) & 176.26 & 0.191 & 331.00 \\
\hline Fat (g of total kcal) & 173.72 & 0.217 & 326.77 \\
\hline SFA (g of total kcal) & 176.48 & 0.206 & 329.38 \\
\hline MUFA (g of total kcal) & 173.72 & 0.217 & 326.77 \\
\hline PUFA (g of total kcal) & 176.49 & 0.176 & 325.39 \\
\hline n-6 PUFA (gr/day) & 176.50 & 0.206 & 329.39 \\
\hline n-3 PUFA (gr/day) & 176.48 & 0.085 & 309.38 \\
\hline
\end{tabular}

A $p$ value in bold type denotes a significant difference $(p<0.05)$. Abbreviation: BMI, Body Mass Index; WC, Waist Circumference; SBP, Systolic Blood Pressure; DBP, Diastolic Blood Pressure; HDL, High-Density Lipoprotein; LDL, Low-Density Lipoprotein; R, Resistance; Xc, Reactance; PhA, Phase angle; PREDIMED, PREvención con DIeta MEDiterránea; SFA, Saturated Fatty Acids; MUFA, MonoUnsaturated Fatty Acids; PUFA, PolyUnsaturated Fatty Acids.

Correlations among ki67\% index and tumor size with age, anthropometric measurement, blood pressure, metabolic profile, bioelectrical variables and nutritional assessment, are summarized in Table S3. ki67\% showed significant correlations with all anthropometric measurements ( $p=0.002$ for BMI and $p<0.001$ for WC), metabolic profile $(p<0.001)$, SBP $(p=0.003)$, PhA and PREDIMED score $(p<0.001)$. Tumor size correlated with SBP $(p=0.040)$, HDL cholesterol $(p=0.018), \operatorname{PhA}(p=0.001)$, PREDIMED score $(p<0.001)$, and protein consumption $(p=0.036)$. After adjusting for BMI and WC, all correlations for both ki67\% and tumor size were maintained, except those with SBP (Table S3).

Three multiple linear regression analysis models including variables statistically correlated with each oncological category (grading, tumor stage, and disease status) were performed to compare the relative predictive power of the evaluated variables (Table 7).

Model 1 compared the relative predictive power of grading G1/G2 on WC, SBP, fasting glucose, total cholesterol, HDL cholesterol, LDL cholesterol, triglycerides, PhA, PREDIMED score, protein, and simple carbohydrate consumption. Using this model the PREDIMED score entered at the first step $(p<0.001)$, followed by PhA $(p<0.001)$, and simple carbohydrate $(p=0.005)$. Model 2 compared the relative predictive power of metastases (stage IV) on WC, SBP, DBP, fasting glucose, HDL cholesterol, triglycerides, PhA, and PREDIMED score. Using this model, triglycerides entered at the first step $(p<0.001)$, followed by the PREDIMED score $(p=0.003)$. In the model 3 , the disease status was better predicted by PREDIMED score $(p<0.001)$ (Table 7). 
Table 7. Multiple regression analysis models (stepwise method) with tumor aggressiveness and nutritional parameters.

\begin{tabular}{|c|c|c|c|c|}
\hline \multicolumn{5}{|c|}{ Multiple Regression Analysis } \\
\hline Model 1-Tumor Grading- & $\mathbf{R}^{2}$ & $\beta$ & $\mathbf{t}$ & $p$ value \\
\hline PREDIMED score & 0.591 & -0.724 & -9.45 & $<0.001$ \\
\hline $\operatorname{PhA}\left({ }^{\circ}\right)$ & 0.595 & -0.394 & -4.04 & $<0.001$ \\
\hline Simple carbohydrate (g of total kcal) & 0.629 & 0.194 & 2.88 & 0.005 \\
\hline LDL cholesterol (mg/dL) & 0.646 & 0.171 & 2.19 & 0.031 \\
\hline \multicolumn{5}{|c|}{ Variable excluded: WC, SBP, fasting Glucose, total cholesterol, HDL cholesterol, triglycerides, Xc, protein (g of total kcal } \\
\hline Model 2-Tumor Stage- & $\mathbf{R}^{2}$ & $\beta$ & $\mathbf{t}$ & $p$ value \\
\hline Triglycerides (mg/dL) & 0.151 & 0.402 & 3.95 & $<0.001$ \\
\hline PREDIMED score & 0.232 & -0.306 & -3.08 & 0.003 \\
\hline \multicolumn{5}{|c|}{ Variable excluded: WC, SBP, DBP, fasting Glucose, HDL cholesterol, PhA. } \\
\hline Model 3-Disease Status- & $\mathbf{R}^{2}$ & $\beta$ & $\mathbf{t}$ & $p$ value \\
\hline PREDIMED score & 0.152 & -0.403 & -3.96 & $<0.001$ \\
\hline Variable excluded: & P, DBP, & e, HDL c & glycerid & \\
\hline
\end{tabular}

A $p$ value in bold type denotes a significant difference $(p<0.05)$. Abbreviation: PREDIMED, PREvención con DIeta MEDiterránea; PhA, Phase angle; LDL, Low-Density Lipoprotein; WC, Waist Circumference; SBP, Systolic Blood

Pressure; HDL, High-Density Lipoprotein; Xc, Reactance; DBP, Diastolic Blood Pressure.

The multiple linear regression analysis models including variables statistically correlating with ki67\% index and tumor size, were reported in Table S4. In the model 1, ki67\% index was better predicted by PhA $(p<0.001)$; in model 2 the dimension of lesion was better predicted by PREDIMED score $(p<0.001)$ (Table S4).

ROC analysis was performed to determine the cut off values of the PREDIMED score and PhA predictive of high grading, metastases, and disease status. A PREDIMED score $\leq 5(p<0.001$, sensitivity $80 \%$, specificity $95.8 \%$; Figure $3 \mathrm{~A})$ and a $\mathrm{PhA} \leq 4.7^{\circ}(p<0.001$, sensitivity $94.3 \%$, specificity $81.2 \%$, Figure $3 \mathrm{~B}$ ), could serve as thresholds for significant increased risk of G2 tumor.

A)

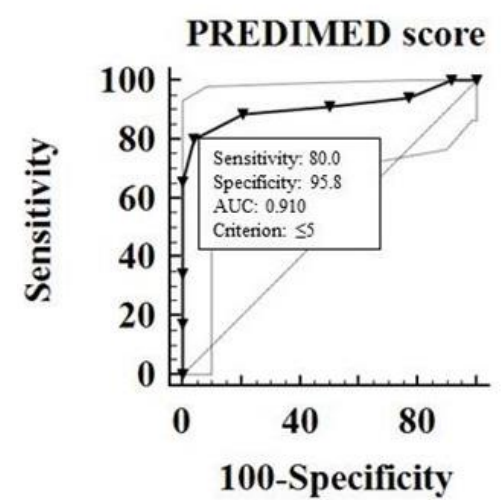

B)

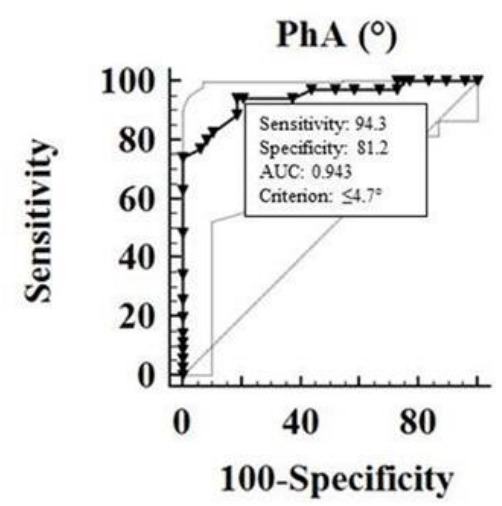

Figure 3. ROC analysis was performed to determine the cut off values of the PREDIMED score (A) and $\mathrm{PhA}(\mathbf{B})$ predictive for the evaluation of increased risk of grading G2. Abbreviation: PREDIMED, PREvención con DIeta MEDiterránea; PhA, phase angle; ROC, Receiver operator characteristic.

A PREDIMED score $\leq 4$ could serve as a threshold for significantly increased risk of metastases $(p<0.001$, sensitivity 54.5\%, specificity 82\%; Figure 4A). A PREDIMED score $\leq 5$ was associated with a significant increased risk of progressive disease during follow-up ( $p<0.001$, sensitivity 71.4\%, specificity $75.8 \%$; Figure 4B). 
A) Metastases

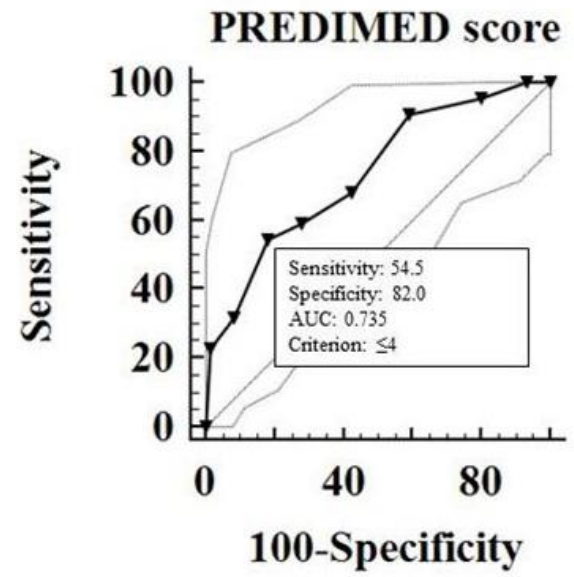

B) Disease status

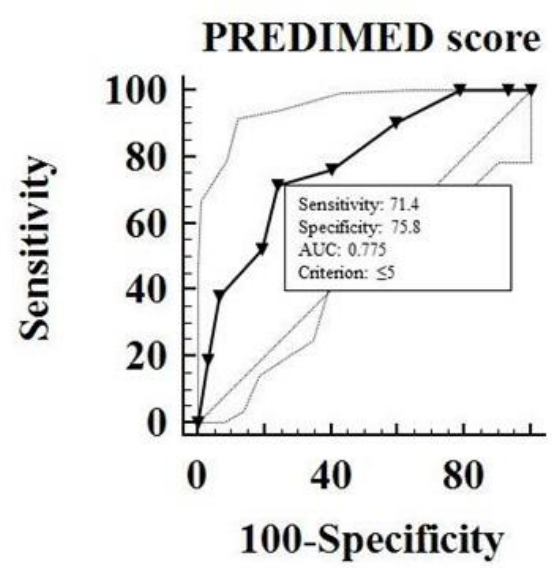

Figure 4. ROC analysis to determine the cut off values of the PREDIMED score for the evaluation of increased risk of metastases (A) and progressive disease (B). Abbreviation: PREDIMED, PREvención con DIeta MEDiterránea; PhA, phase angle; ROC, Receiver operator characteristic.

\section{Discussion}

GEP-NET patients have been reported to have an impaired nutritional status (the metabolic state, the dietary pattern and body composition), mostly due to excessive secretion of gastrointestinal hormones and peptides, medical treatment, and surgical procedures $[4,40]$. Different studies have shown that a poor nutritional status negatively impacts the clinical outcome of patients with NET [6,8,9]. Moreover, metabolic profile has been reported to worsen the severity of non-functioning GEP-NETs being associated to a higher ki67\% index and larger tumor size [5]. It has been suggested that nutritional factors, such as the adherence to the MD, could influence the aggressiveness of different tumor types, such as prostate, bladder and breast cancer [12-14], and that a low adherence to the MD pattern could correlate with an increased risk of metabolic syndrome [16].

In our study we reported the difference of nutritional status, evaluated by BIA and its derived parameter PhA, and dietary pattern between a selected group of GEP-NET patients and healthy control. Moreover, in GEP-NET patients we observed a significant correlation among the nutritional status the adherence to the MD and clinicopathological characteristics, including tumor grade, stage, disease status, ki67\% index, and tumor size.

In comparison to healthy controls, patients affected by GEP-NET had a dietary pattern characterized by a significantly lower adherence to the MD, as assessed by PREDIMED score, consuming less frequently vegetables, fruits, wine, fish/seafood, nuts, and more frequently red/processed meats, butter, cream, margarine, and soda drinks. Moreover, in line with the tumor-preventive potential effect of some food containing specific bioactive compounds (e.g., n-3 PUFA, or MUFA) [41], we observed that GEP-NET patients in comparison to healthy controls, had a lower consumption of unsaturated fat that is beneficial for health, were associated with a lower consumption of plant protein and complex carbohydrates and had a preferential consumption of simple carbohydrate and n-6 PUFA. As already reported [16], we observed that GEP-NET patients presented a worse metabolic profile probably as a consequence of a low adherence to the MD. Indeed, the metabolic profile of these patients was characterized by an increase of waist circumference, higher blood pressure values, and significantly higher blood levels of fasting glucose, total and LDL cholesterol and triglycerides, and significantly lower levels of HDL cholesterol, all parameters that are associated with a higher risk of metabolic syndrome. Thus, we confirmed that the worse metabolic parameters correlated with higher ki67\% index, as previously reported by our group [5]. However, we did not find significant correlations between these parameters and larger tumor size, except for HDL cholesterol. These contrasting results with our previous study [5] could be due to the fact that in the present study 
we did not consider the metabolic syndrome per se, but we focused our attention on the nutritional status and dietary pattern.

We observed that GEP-NET patients presented a decreased PhA value in comparison to healthy controls, as already reported in other diseases, such as infection disease, inflammation status, and several cancer types [11]. It has been suggested that the PhA value correlated with disease severity [11] and that a low value could be predictive of impaired prognosis (mortality, disease progression, postoperative complications) in different tumors, such as pancreatic [42], breast [43], lung [44], and colorectal cancer [45]. Moreover, we recently observed that PhA value correlated with the adherence to MD independently of confounding factors [17]. In parallel with these findings, we demonstrated that a decreased PhA, together with a lower adherence to the MD as assessed by a low PREDIMED score, were the major predictors of GEP-NET aggressiveness. The ROC analysis showed that tumor grading G2 was well predicted by a PREDIMED score $\leq 5$ and a PhA value $\leq 4.7^{\circ}$ with a sensitivity of $80 \%$ and $94.3 \%$ and a specificity of $95.8 \%$ and $81.2 \%$, respectively. Thus, we concluded that a lower adherence to the MD, together with a decreased PhA value and a consequent worse metabolic profile, were associated with an increased GEP-NET aggressiveness, characterized by tumor grading G2, stage IV and progressive disease, also after adjustments for gender, smoking, and physical activity.

However, there are some limits of this study that should be considered. The cross-sectional nature of the study did not allow any causal association to be identified between MD or PhA and GEP-NETs and to clearly determine the prognostic value of the adherence to the MD or of PhA for predicting its clinical severity. Moreover, the suggested cut-off value of the PREDIMED score and PhAs to identify tumor aggressiveness should be viewed with caution until results in larger populations become available to perform an appropriate cross-validation. In addition, expert nutritionists are required for the assessment, execution, and interpretation of BIA measurements, such as PhA. The main strength of this study was the use of the 7-day food records. This method is the "gold standard" in validation studies of different self-administered food frequency questionnaires and allows a more accurate measurement of the dietary and macronutrient intakes compared to other questionnaires [46,47]. In order to improve the power of the study, we increased the homogeneity of the cohort of studied patients by including non-functioning treatment-naïve patients or patients who underwent curative surgery and who were biochemically free of disease for more than 6 month and who had not partaken of medical treatment. Moreover, all patients had a diagnosis of well-differentiated G1/G2 GEP-NET and both GEP-NET patients and matched controls were well characterized.

\section{Conclusions}

In conclusion, to the best of our knowledge, this is the first study to show a novel association between nutritional status and aggressiveness of GEP-NETs in a selected cohort of adult patients. This association potentially extends the benefit of adherence to the MD to GEP-NET patients and suggests that BIA and PhA value may be used as tools for the nutritional management of these patients and as markers of tumor aggressiveness. Moreover, this is the first study to indicate a dietary pattern that may be beneficial for GEP-NET patients and that may modulate the risk of tumor aggressiveness, offering a practical strategy for the management of these patients. Therefore, the assessment of nutritional status should be recommended as good clinical practice in the evaluation of GEP-NET patients, in order to identify high-risk subjects with a more aggressive tumor who could better benefit from a nutritional intervention promoting the Mediterranean food pattern. Thus, a skilled nutritionist should be part of the multidisciplinary health care team in NETs management, adapting the specific nutritional needs to the course of the disease. Future well-designed dietary intervention trials on larger population samples are needed to define specific dietary guidelines for NETs and elucidate the beneficial effects of the MD on the survival outcomes of GEP-NET patients.

Supplementary Materials: The following are available online at http:/ / www.mdpi.com/2072-6643/10/12/1854/ s1, Table S1: Total energy and daily macronutrients/micronutrients intake of GEP-NET patients and control group, Table S2: Grading, disease stage and disease status in GEP-NET patients according to gender, gender, 
smoking, physical activity and PREDIMED categories, Table S3: Correlations of ki67\% index and tumor size with demographic, clinical, metabolic and bioelectrical parameters, Table S4: Multiple regression analysis models (stepwise method) with the tumor aggressiveness and nutritional parameters.

Author Contributions: The author's responsibilities were as follow: Conceptualization, L.B., A.F. and S.S.; Data curation, L.B., B.A., D.L. and G.A.; Formal analysis, L.B. and S.S.; Funding acquisition, A.C. and A.F.; Investigation, L.B., B.A., G.M., D.L., G.A., A.C., A.F. and S.S.; Methodology, L.B., G.M., A.C. and S.S.; Project administration, L.B., A.C. and S.S.; Resources, A.C., A.F. and S.S.; Software, G.A.; Supervision, L.B.; Visualization, B.A. and G.A.; Writing-original draft, L.B. and B.A.

Funding: This research received no external funding.

Acknowledgments: We would like to thank Angela Avino for data retrieval.

Conflicts of Interest: The authors declare no conflict of interest.

\section{References}

1. Dasari, A.; Shen, C.; Halperin, D.; Zhao, B.; Zhou, S.; Xu, Y.; Shih, T.; Yao, J.C. Trends in the Incidence, Prevalence, and Survival Outcomes in Patients With Neuroendocrine Tumors in the United States. JAMA Oncol. 2017, 3, 1335-1342. [CrossRef] [PubMed]

2. Faggiano, A.; Ferolla, P.; Grimaldi, F.; Campana, D.; Manzoni, M.; Davi, M.V.; Bianchi, A.; Valcavi, R.; Papini, E.; Giuffrida, D.; et al. Natural history of gastro-entero-pancreatic and thoracic neuroendocrine tumors. Data from a large prospective and retrospective Italian epidemiological study: The NET management study. J. Endocrinol. Invest. 2012, 35, 817-823. [CrossRef] [PubMed]

3. Falconi, M.; Eriksson, B.; Kaltsas, G.; Bartsch, D.K.; Capdevila, J.; Caplin, M.; Kos-Kudla, B.; Kwekkeboom, D.; Rindi, G.; Kloppel, G.; et al. ENETS Consensus Guidelines Update for the Management of Patients with Functional Pancreatic Neuroendocrine Tumors and Non-Functional Pancreatic Neuroendocrine Tumors. Neuroendocrinology 2016, 103, 153-171. [CrossRef] [PubMed]

4. Go, V.L.; Srihari, P.; Kamerman Burns, L.A. Nutrition and gastroenteropancreatic neuroendocrine tumors. Endocrinol. Metab. Clin. N. Am. 2010, 39, 827-837. [CrossRef] [PubMed]

5. Gallo, M.; Muscogiuri, G.; Pizza, G.; Ruggeri, R.M.; Barrea, L.; Faggiano, A.; Colao, A.; Group, N. The management of neuroendocrine tumours: A nutritional viewpoint. Crit. Rev. Food Sci. Nutr. 2017, 1-12. [CrossRef] [PubMed]

6. Glazer, E.; Stanko, K.; Ong, E.; Guerrero, M. Decreased Inpatient Mortality in Obese Patients with Abdominal Nets. Endocr. Pract. 2014, 20, 1-20. [CrossRef] [PubMed]

7. Ekeblad, S.; Skogseid, B.; Dunder, K.; Oberg, K.; Eriksson, B. Prognostic factors and survival in 324 patients with pancreatic endocrine tumor treated at a single institution. Clin. Cancer Res. 2008, 14, 7798-7803. [CrossRef] [PubMed]

8. Maasberg, S.; Knappe-Drzikova, B.; Vonderbeck, D.; Jann, H.; Weylandt, K.H.; Grieser, C.; Pascher, A.; Schefold, J.C.; Pavel, M.; Wiedenmann, B.; et al. Malnutrition Predicts Clinical Outcome in Patients with Neuroendocrine Neoplasia. Neuroendocrinology 2017, 104, 11-25. [CrossRef] [PubMed]

9. Marrache, F.; Vullierme, M.P.; Roy, C.; El Assoued, Y.; Couvelard, A.; O’Toole, D.; Mitry, E.; Hentic, O.; Hammel, P.; Levy, P.; et al. Arterial phase enhancement and body mass index are predictors of response to chemoembolisation for liver metastases of endocrine tumours. Br. J. Cancer 2007, 96, 49-55. [CrossRef] [PubMed]

10. Barbosa-Silva, M.C.; Barros, A.J.; Wang, J.; Heymsfield, S.B.; Pierson, R.N., Jr. Bioelectrical impedance analysis: Population reference values for phase angle by age and sex. Am. J. Clin. Nutr. 2005, 82, 49-52. [CrossRef] [PubMed]

11. Norman, K.; Stobaus, N.; Pirlich, M.; Bosy-Westphal, A. Bioelectrical phase angle and impedance vector analysis-clinical relevance and applicability of impedance parameters. Clin. Nutr. 2012, 31, 854-861. [CrossRef] [PubMed]

12. Pascual-Geler, M.; Urquiza-Salvat, N.; Cozar, J.M.; Robles-Fernandez, I.; Rivas, A.; Martinez-Gonzalez, L.J.; Ocana-Peinado, F.M.; Lorente, J.A.; Alvarez-Cubero, M.J. The influence of nutritional factors on prostate cancer incidence and aggressiveness. Aging Male 2018, 21, 31-39. [CrossRef] [PubMed] 
13. Buckland, G.; Ros, M.M.; Roswall, N.; Bueno-de-Mesquita, H.B.; Travier, N.; Tjonneland, A.; Kiemeney, L.A.; Sacerdote, C.; Tumino, R.; Ljungberg, B.; et al. Adherence to the Mediterranean diet and risk of bladder cancer in the EPIC cohort study. Int. J. Cancer 2014, 134, 2504-2511. [CrossRef] [PubMed]

14. Escrich, E.; Moral, R.; Solanas, M. Olive oil, an essential component of the Mediterranean diet, and breast cancer. Public Health Nutr. 2011, 14, 2323-2332. [CrossRef] [PubMed]

15. Schwingshackl, L.; Schwedhelm, C.; Galbete, C.; Hoffmann, G. Adherence to Mediterranean Diet and Risk of Cancer: An Updated Systematic Review and Meta-Analysis. Nutrients 2017, 9, 1063. [CrossRef] [PubMed]

16. Kastorini, C.M.; Milionis, H.J.; Esposito, K.; Giugliano, D.; Goudevenos, J.A.; Panagiotakos, D.B. The effect of Mediterranean diet on metabolic syndrome and its components: A meta-analysis of 50 studies and 534,906 individuals. J. Am. Coll. Cardiol. 2011, 57, 1299-1313. [CrossRef] [PubMed]

17. Barrea, L.; Muscogiuri, G.; Macchia, P.E.; Di Somma, C.; Falco, A.; Savanelli, M.C.; Colao, A.; Savastano, S. Mediterranean Diet and Phase Angle in a Sample of Adult Population: Results of a Pilot Study. Nutrients 2017, 9, 151. [CrossRef] [PubMed]

18. Rindi, G.; Arnold, R.; Capella, C.; Klimstra, D.S.; Klöppel, G.; Komminoth, P.; Solcia, E. Nomenclature and classification of digestive neuroendocrine tumours. In World Health Organization Classification of Tumours, Pathology and Genetics of Tumours of the Digestive System; Bosman, F., Lyon, F.C.I., Eds.; IARC: Lyons, France, 2010.

19. Association, A.P. Diagnostic and Statistical Manual of Mental Disorders, 5th ed.; American Psychiatric Association: Washington, DC, USA, 2013.

20. Rindi, G.; Kloppel, G.; Alhman, H.; Caplin, M.; Couvelard, A.; de Herder, W.W.; Erikssson, B.; Falchetti, A.; Falconi, M.; Komminoth, P.; et al. TNM staging of foregut (neuro)endocrine tumors: A consensus proposal including a grading system. Virchows Arch. 2006, 449, 395-401. [CrossRef] [PubMed]

21. Inzani, F.; Petrone, G.; Fadda, G.; Rindi, G. Cyto-histology in NET: What is necessary today and what is the future? Rev. Endocr. Metab. Disord. 2017, 18, 381-391. [CrossRef] [PubMed]

22. Circelli, L.; Sciammarella, C.; Guadagno, E.; Tafuto, S.; del Basso de Caro, M.; Botti, G.; Pezzullo, L.; Aria, M.; Ramundo, V.; Tatangelo, F.; et al. CXCR4/CXCL12/CXCR7 axis is functional in neuroendocrine tumors and signals on mTOR. Oncotarget 2016, 7, 18865-18875. [CrossRef] [PubMed]

23. Eisenhauer, E.A.; Therasse, P.; Bogaerts, J.; Schwartz, L.H.; Sargent, D.; Ford, R.; Dancey, J.; Arbuck, S.; Gwyther, S.; Mooney, M.; et al. New response evaluation criteria in solid tumours: Revised RECIST guideline (version 1.1). Eur. J. Cancer 2009, 45, 228-247. [CrossRef] [PubMed]

24. Barrea, L.; Di Somma, C.; Macchia, P.E.; Falco, A.; Savanelli, M.C.; Orio, F.; Colao, A.; Savastano, S. Influence of nutrition on somatotropic axis: Milk consumption in adult individuals with moderate-severe obesity. Clin. Nutr. 2017, 36, 293-301. [CrossRef] [PubMed]

25. Barrea, L.; Tarantino, G.; Somma, C.D.; Muscogiuri, G.; Macchia, P.E.; Falco, A.; Colao, A.; Savastano, S. Adherence to the Mediterranean Diet and Circulating Levels of Sirtuin 4 in Obese Patients: A Novel Association. Oxid. Med. Cell. Longev. 2017, 2017, 6101254. [CrossRef] [PubMed]

26. Barrea, L.; Macchia, P.E.; Tarantino, G.; Di Somma, C.; Pane, E.; Balato, N.; Napolitano, M.; Colao, A.; Savastano, S. Nutrition: A key environmental dietary factor in clinical severity and cardio-metabolic risk in psoriatic male patients evaluated by 7-day food-frequency questionnaire. J. Transl. Med. 2015, 13, 303. [CrossRef] [PubMed]

27. Barrea, L.; Muscogiuri, G.; Di Somma, C.; Annunziata, G.; Megna, M.; Falco, A.; Balato, A.; Colao, A.; Savastano, S. Coffee consumption, metabolic syndrome and clinical severity of psoriasis: Good or bad stuff? Arch. Toxicol. 2018, 92, 1831-1845. [CrossRef] [PubMed]

28. Turconi, G.; Guarcello, M.; Berzolari, F.G.; Carolei, A.; Bazzano, R.; Roggi, C. An evaluation of a colour food photography atlas as a tool for quantifying food portion size in epidemiological dietary surveys. Eur. J. Clin. Nutr. 2005, 59, 923-931. [CrossRef] [PubMed]

29. Barrea, L.; Balato, N.; Di Somma, C.; Macchia, P.E.; Napolitano, M.; Savanelli, M.C.; Esposito, K.; Colao, A.; Savastano, S. Nutrition and psoriasis: Is there any association between the severity of the disease and adherence to the Mediterranean diet? J. Transl. Med. 2015, 13, 18-27. [CrossRef] [PubMed]

30. Barrea, L.; Muscogiuri, G.; Di Somma, C.; Tramontano, G.; De Luca, V.; Illario, M.; Colao, A.; Savastano, S. Association between Mediterranean diet and hand grip strength in older adult women. Clin. Nutr. 2018. [CrossRef] [PubMed] 
31. Savanelli, M.C.; Barrea, L.; Macchia, P.E.; Savastano, S.; Falco, A.; Renzullo, A.; Scarano, E.; Nettore, I.C.; Colao, A.; Di Somma, C. Preliminary results demonstrating the impact of Mediterranean diet on bone health. J. Transl. Med. 2017, 15, 81. [CrossRef] [PubMed]

32. Vuolo, L.; Barrea, L.; Savanelli, M.C.; Savastano, S.; Rubino, M.; Scarano, E.; Soprano, M.; Illario, M.; Colao, A.; Di Somma, C. Nutrition and Osteoporosis: Preliminary data of Campania Region of European PERsonalised ICT Supported Service for Independent Living and Active Ageing. Transl. Med. UniSa. 2015, 13, 13-18. [PubMed]

33. Martinez-Gonzalez, M.A.; Garcia-Arellano, A.; Toledo, E.; Salas-Salvado, J.; Buil-Cosiales, P.; Corella, D.; Covas, M.I.; Schroder, H.; Aros, F.; Gomez-Gracia, E.; et al. A 14-item Mediterranean diet assessment tool and obesity indexes among high-risk subjects: The PREDIMED trial. PLoS ONE 2012, 7, e43134. [CrossRef] [PubMed]

34. World Health Organization. Waist Circumference and Waist-Hip Ratio. Report of a WHO Expert Consultation, Geneva, 8-11 December 2008; World Health Organization: Geneva, Switzerland, 2008.

35. Nishida, C.; Ko, G.T.; Kumanyika, S. Body fat distribution and noncommunicable diseases in populations: Overview of the 2008 WHO Expert Consultation on Waist Circumference and Waist-Hip Ratio. Eur. J. Clin. Nutr. 2010, 64, 2-5. [CrossRef] [PubMed]

36. Yanovski, J.A.; Yanovski, S.Z.; Filmer, K.M.; Hubbard, V.S.; Avila, N.; Lewis, B.; Reynolds, J.C.; Flood, M. Differences in body composition of black and white girls. Am. J. Clin. Nutr. 1996, 64, 833-839. [CrossRef] [PubMed]

37. Barrea, L.; Macchia, P.E.; Di Somma, C.; Napolitano, M.; Balato, A.; Falco, A.; Savanelli, M.C.; Balato, N.; Colao, A.; Savastano, S. Bioelectrical phase angle and psoriasis: A novel association with psoriasis severity, quality of life and metabolic syndrome. J. Transl. Med. 2016, 14, 130-141. [CrossRef] [PubMed]

38. Kyle, U.G.; Bosaeus, I.; De Lorenzo, A.D.; Deurenberg, P.; Elia, M.; Manuel Gomez, J.; Lilienthal Heitmann, B.; Kent-Smith, L.; Melchior, J.C.; Pirlich, M.; et al. Bioelectrical impedance analysis-part II: Utilization in clinical practice. Clin. Nutr. 2004, 23, 1430-1453. [CrossRef] [PubMed]

39. Kushner, R.F. Bioelectrical impedance analysis: A review of principles and applications. J. Am. Coll. Nutr. 1992, 11, 199-209. [PubMed]

40. Altieri, B.; Barrea, L.; Modica, R.; Muscogiuri, G.; Savastano, S.; Colao, A.; Faggiano, A. Nutrition and neuroendocrine tumors: An update of the literature. Rev. Endocr. Metab. Disord. 2018, 19, 159-167. [CrossRef] [PubMed]

41. Milner, J.A. Molecular targets for bioactive food components. J. Nutr. 2004, 134, S2492-S2498. [CrossRef] [PubMed]

42. Gupta, D.; Lis, C.G.; Dahlk, S.L.; Vashi, P.G.; Grutsch, J.F.; Lammersfeld, C.A. Bioelectrical impedance phase angle as a prognostic indicator in advanced pancreatic cancer. Br. J. Nutr. 2004, 92, 957-962. [CrossRef] [PubMed]

43. Gupta, D.; Lammersfeld, C.A.; Vashi, P.G.; King, J.; Dahlk, S.L.; Grutsch, J.F.; Lis, C.G. Bioelectrical impedance phase angle as a prognostic indicator in breast cancer. BMC Cancer 2008, 8, 249. [CrossRef] [PubMed]

44. Toso, S.; Piccoli, A.; Gusella, M.; Menon, D.; Bononi, A.; Crepaldi, G.; Ferrazzi, E. Altered tissue electric properties in lung cancer patients as detected by bioelectric impedance vector analysis. Nutrition 2000, 16, 120-124. [CrossRef]

45. Gupta, D.; Lammersfeld, C.A.; Burrows, J.L.; Dahlk, S.L.; Vashi, P.G.; Grutsch, J.F.; Hoffman, S.; Lis, C.G. Bioelectrical impedance phase angle in clinical practice: Implications for prognosis in advanced colorectal cancer. Am. J. Clin. Nutr. 2004, 80, 1634-1638. [CrossRef] [PubMed]

46. Hu, F.B. Dietary pattern analysis: A new direction in nutritional epidemiology. Curr. Opin. Lipidol. 2002, 13, 3-9. [CrossRef] [PubMed]

47. Hoidrup, S.; Andreasen, A.H.; Osler, M.; Pedersen, A.N.; Jorgensen, L.M.; Jorgensen, T.; Schroll, M.; Heitmann, B.L. Assessment of habitual energy and macronutrient intake in adults: Comparison of a seven day food record with a dietary history interview. Eur. J. Clin. Nutr. 2002, 56, 105-113. [CrossRef] [PubMed]

(C) 2018 by the authors. Licensee MDPI, Basel, Switzerland. This article is an open access article distributed under the terms and conditions of the Creative Commons Attribution (CC BY) license (http:/ / creativecommons.org/licenses/by/4.0/). 